\title{
La Salud Colectiva: la salud en el contexto de la dignidad humana
}

El modelo médico en la comprensión de la salud imperante en las sociedades occidentales, ha propiciado una visión biologicista, individualista, ahistórica, asocial y pragmática de la salud, la enfermedad y, por ende, de la vida(1). Desde esta perspectiva, la salud explicada como una situación antagónica a la enfermedad, orienta diferentes corrientes teórico-metodológicas que, desde un discurso positivista, buscan medir y explorar la salud-enfermedad como un objeto de conocimiento aislado de la realidad subjetiva y contextual del cuerposujeto.

En contraposición a estas corrientes, en la segunda mitad del siglo XIX y debido a la revolución industrial y a las transformaciones económicas, sociales, políticas y tecnológicas; con efectos en el bienestar y la salud de las poblaciones, como: la migración del campo a la ciudad, la pauperización, el crecimiento de las clases trabajadoras y la transformación de las dinámicas sociales, se reconoció el vínculo entre la salud y la sociedad, y con ello surgieron nuevas comprensiones en torno a la salud, que trascendieron la mirada biológica, individualista, unicausal y centrada en riesgo.

En América Latina a finales de los años 60 y comienzos de los 70, bajo la influencia del pensamiento marxista, la revolución cubana, los movimientos sociales y la lucha por la soberanía de los pueblos, se desarrolló el movimiento de la medicina social y la salud colectiva, con la premisa de la comprensión de la salud-enfermedad como un proceso dialéctico que debe ser entendido en el contexto social que los determina(2). La medicina social y la salud colectiva plantean nuevas consideraciones epistemológicas frente al objeto salud, generando saberes y prácticas que incorporan el reconocimiento de los procesos históricos y territoriales, el aporte de las ciencias sociales, la necesidad de abordajes inter y transdisciplinares, interinstitucionales y transectoriales, la participación social y comunitaria, entre otros, como caminos para la equidad y el bienestar humano.

Desde un carácter ético-político, la salud colectiva busca aportar en la comprensión y solución de las problemáticas y demandas sociales, mediante procesos que permitan incidir en la pobreza, no solo entendida como la carencia de bienes, sino también, como la ausencia de la capacidad de fijar el curso de la vida, y con ello, el desarrollo en los territorios. Esta reconoce a la enfermedad como resultante de las profundas desigualdades existentes entre la población (desigualdades tanto económicas como en el acceso a los recursos sanitarios, asistenciales y educativos), por esta razón, "entiende que el vivir, el enfermar, el recuperarse y el morir, son producto de la organización de la sociedad, de la estructura de los grupos sociales y, por consiguiente, de la inserción de los sujetos en la sociedad, de la accesibilidad a la salud y a la vida de calidad"(3).

La enfermedad desde su relación con las condiciones de desigualdad e inequidad social, económica y política, que magnifican la vulnerabilidad de las comunidades, permite reconocer que actuar sobre la salud implica además de curar desde un sentido biomédico, la garantía de los derechos fundamentales de las personas, y con ello, el acceso a una vida digna y segura, alimentación, vivienda, trabajo, educación, servicios públicos, entre otros; que contribuya con el desarrollo social.

La salud colectiva como campo de conocimiento y de praxis propone: (a) la noción de la salud-enfermedad como un proceso determinado por una estructura social, económica, política y cultural; (b) la resignificación del rol de los profesionales en salud como agentes de transformación social, quienes, a través del diálogo de saberes con otros actores sociales, construyen conocimientos e impulsan procesos para aportar en el buen vivir de las poblaciones; (c) la intersectorialidad y transdisciplinariedad como mecanismos para comprender y abordar realidades complejas; (d) la participación comunitaria, cuyo carácter político ejerce una la función desalienante, movilizadora y transformadora; (e) la necesidad de métodos contextualizados a las realidades y características de las comunidades y los sujetos, que respondan a las dinámicas sociales y a sus efectos individuales y colectivos, y (f) el carácter ético-político para el desarrollo de procesos que aporten a la transformación social.

Ante la crisis sin precedentes que hoy vivimos, derivada de los efectos de la globalización económica, tecnológica, cultural y política, con serias repercusiones epidemiológicas, éticas, sanitarias, ambientales, de 
poder y de equidad sobre la salud, se hacen necesarios nuevos marcos de interpretación y actuación; por ello, la salud colectiva, se vislumbra como un camino para avanzar en la construcción de una cultura de la salud como derecho y bien social en estrecha conexión con la vida(4).

En países como Colombia, con un sistema de salud basado en un esquema de aseguramiento, en el que persisten problemas como la desigualdad por niveles de riqueza, diferencias en el acceso efectivo y equitativo entre poblaciones urbanas y rurales, respuesta de la oferta de servicios de salud fraccionada, problemas de acceso y calidad en la prestación de sus servicios, baja capacidad técnica y de gestión por parte de las entidades territoriales, una cultura institucional del trabajo individual y el enfoque tradicional centrado en el riesgo(5); la salud colectiva se constituye en una respuesta y forma de resistencia al modelo, desde una nueva concepción de la salud, el rol de los actores y la vinculación de distintos sectores sociales con el fin de procurar la garantía del ejercicio de los derechos humanos y sociales como un imperante para la superación de las inequidades y desigualdades, y la construcción de sociedades en paz.

En el municipio de Pasto, como producto del trabajo mancomunado intersectorial e interinstitucional, se construyó la Política Pública de Salud Colectiva "La salud en todos los derechos 2019 -2032", que reconoce a la salud desde su carácter histórico y contextual, cuya garantía requiere de la participación y articulación comunitaria, institucional e intersectorial. Esta política pública es pionera en Colombia, por ello, se constituye en una apuesta de territorio para lograr nuevas comprensiones y prácticas en torno a la salud, que, desde un sentido ético, político, equitativo y democrático, reconoce la garantía de este derecho en interdependencia con otros derechos, como un imperante para la vida digna.

La política cuenta con cuatro ejes: (a) saludable o bioseguridad; (b) soberanía; (c) solidaridad y (d) sustentabilidad; y ocho líneas de acción: (a) gestión social del conocimiento, investigación e innovación social en salud; (b) participación política y comunitaria; (c) ambiental; (d) pedagogía, comunicación y movilización social; (e) reivindicación de los procesos ancestrales y tradicionales emancipadores;(f) emprendimiento; (g) prestación de servicios de salud y género y diversidad. Sus ejes y líneas de acción, están orientados a lograr la satisfacción y garantía del derecho a la salud en interdependencia con otros derechos humanos, derechos de segunda y tercera generación, entorno al mejoramiento de los modos de vida saludables individuales y colectivos(6)

Esta apuesta del municipio de Pasto traza un horizonte hacia el buen vivir, al ser un mecanismo articulador entre las comunidades, las instituciones y el Estado. No obstante, en el contexto actual del país y bajo el esquema del sistema de salud, también se constituye en un reto, cuyo desarrollo requiere de la voluntad política de los tomadores de decisiones, la participación activa de las comunidades, la intersectorialidad e interinstitucionalidad, así como el reconocimiento de la salud como un derecho y como un proceso determinado por las condiciones de vida de las personas, esto es: vivienda, educación, trabajo, cultura, territorio, entre otros.

\section{Mg. Melissa Ricaurte-Cepeda Grupo de Investigación Salud Pública}

\section{Referencias}

1. Baeta S. MF. Cultura y Modelo Biomédico: Reflexiones en el proceso de Salud-Enfermedad. Comunidad y Salud [Internet]. 2015;13(2):81-3. Available from: http://www.redalyc.org/articulo.oa?id=375743552011

2. Iriart C, Waitzkin H, Breilh J, Estrada A, Merhy EE. Medicina social latinoamericana: aportes y desafíos. Rev Panam Salud Publica [Internet]. 2002;12(2):128-36. Available from: https://www.scielosp.org/scielo.php?pid=S102049892002000800013\&script=sci_abstract\#ModalArticles

3. Bertolozzi MR, De-La-Torre-Ugarte-Guanilo MC. Salud colectiva: fundamentos conceptuales. Salud Areandina [Internet]. 2012 Jul 6;1(1):24-36. Available from: https://revia.areandina.edu.co/index.php/Nn/article/view/309

4. Franco G. A. La globalización de la salud: entre el reduccionismo económico y la solidaridad ciudadana (segunda parte). Rev Fac Nac Salud Pública [Internet]. 2002;20(2):103-18. Available from: https://pesquisa.bvsalud.org/portal/resource/pt/lil-323907?lang=es

5. Ministerio de Salud y Protección Social. Política de atención integral en salud [Internet]. Bogotá D.C.; 2016. Available from: https://www.minsalud.gov.co/Documentos y Publicaciones/Política de Atención Integral en Salud.pdf

6. Concejo Municipal de Pasto. Acuerdo No. 035 Por medio del cual se adopta la Política Pública En Salud Colectiva "La Salud en Todos los Derechos 2019 - 2032" [Internet]. San Juan de Pasto; 2019. Available from: www.concejodepasto.gov.co 